\title{
On the Hypothesis that Lake Tanganyika represents an Old Jurassic Sea.
}

By

\section{J. E. S. Moore.}

With Plate 23.

"For anything that geology or palæontology can show to the contrary, a Devonian fauna and flora in the British Islands may have been contemporaneous with the Silurian life in North America, and with a Carboniferous fauna in Africa. Geological provinces and zones may have been as clearly marked in the Palæozoic epoch as at present, and those seemingly sudden appearances of new genera and species which we ascribe to new creation may be simply due to migration."

If the statements contained in this remarkable passage express the truth-and no one acquainted with the forcible arguments which Huxley brought forward ${ }^{1}$ in their support will doubt that such is actually the case-it follows as a sort of natural corollary that the existence of our modern fauna and flora may not be incompatible with the co-existence in certain places of extremely ancient types. In several former papers $\mathrm{I}^{2}$ have laid especial emphasis upon the very singular fact that the fauna of Lake Tanganyika is a double series, that it is in reality composed of two entirely dissimilar faunas which coexist in the great lake side by side.

1 Anniversary address to the Geological Society, 1862.

2 'Nature,' July, 1897, p. 198; 'Science Progress,' October, 1897 ; “ The Molluses of the Great African Lakes :-Distribution." 'Quart. Journ. Micr. Sci.,' vol. 41, pp. 159-180. 
$I^{1}$ have shown that one of these two faunas consists of the normal and ubiquitous fresh-water stock, which is distributed throughout the whole African continent, and indeed throughout the world. The second fauna is altogether different from this, and in the appearance of its widely divergent constituents is utterly unlike any modification of the normal fresh-water fauna that is known. It has long ago been recognised that the superficial facies of the molluscan shells belonging to this series are those of a marine rather than a fresh-water stock, and in recognition of the more complete marine affinities which a closer scrutiny of the internal anatomy of these animals has revealed, $\mathrm{I}^{2}$ have here, as elsewhere, spoken of the whole series of forms in Tanganyika which exhibit these quasimarine characters as members of the halolimnic group. ${ }^{3}$

1 "On the Zoological Evidence for the Connection of Lake Tanganyika with the Sea," 'Proc. Roy. Soc.,' vol. Ixii, 1898, pp. 452-458.

2 "The Molluscs of the Great African Lakes.-II. The Anatomy of the Typhobias, \&c.,' 'Quart. Journ. Micr. Sci.,' vol. 41, 1898, pp. 181-202.

3 If the practical distinction between fresh-water and marine faunas in general were not a well-established and accepted fact, it would have been impossible for geologists to separate, as they have done, fresh-water from marine deposits by the characters of the animals they contain. It is generally assumed that the modern fresh-water fauna has gradually originated far back in time by organisms having one by one acquired characters which have enabled them to successfully colonise fresh water in connection with the sea; but the actual phylogenetic descent of most of the true fresh-water organisms, except in a very broad sense, is lost in antiquity and hopelessly obscure. In some Crustacea, in the Ganoids, and some other fishes we have enough palæontological evidence to demonstrate their actual migration from the sea, and such evidence forms part of the ground whence it is argued from analogy that all fresh-water organisms have originated in a similar way. Further evidence of this kind is afforded by those cases, at once remarkable and few, where animals that are generally marine exhibit a wonderful capacity to migrate inland, there being every reason to believe that such organisms constitute the "modern instances" of the origin of new fresh-water types. The true fresh water fauna of any period is thus a heterogeneous assemblage of organisms, all of which have, so to speak, voluntarily acquired the habit of living in fresh-water, and, excepting in this peculiarity, they have no necessary relation with each other. The constant facies which the fresh-water fauna presents all over the world are due primarily to the universal distribution of its heterogeneous constituents, and secondarily to the direct similar effect produced on organisms by a fresh-water life. 
It is perhaps needless for me here to reiterate the great importance of arriving at a final decision as to the real nature of the halolimnic forms, for it will be obvious that if they have nothing to do with the normal fresh-water series, and are to be regarded as the remnant of an ancient sea, our views respecting the past history of the African interior must be greatly changed.

Having obtained the animals, it appeared, therefore, in the first place to be incumbent on me to ascertain, by a careful study of their anatomy, whether this superficially marine appearance was real, and indicative of their common origin from the sea, or whether it was merely, so to speak, skin deep, and to be regarded as wholly the result of modification, or to the persistence of characters which belonged to some old freshwater stock. So far as zoologists are concerned, the evidence which I have now accumulated on this point will be found to be conclusive; but since, with the exception of my paper on the Typhobias (loc. cit.), the detailed accounts of the anatomy of the Halolimnic Gasteropods have not yet been published, I will briefly recapitulate the facts. It has been found ${ }^{1}-$

1 In order that the significance of the new classificatory outline, given in the text immediately below, may be fully appreciated, it should be clearly understood that before my return from Tanganyika no account of the anatomy of any of the halolimnic molluscs was in existence,-indeed, so far as I can ascertain, with the exception of the brief description by Smith of a few badly preserved Nasopses brought home by Captain Hore, the animals contained in any of these shells had never been seen before. Consequently their conchological classification was, as, indeed, Smith frankly implied in 1881, entirely provisional.

All these Halolimnic Gasteropods appear to be rigidly restricted to the confines of Lake Tanganyika, and the only molluses from this lake, halolimnic or otherwise, of which we have had any anatomical description, is the common Reiodon, the morphological characters of which were described by Professor Pelseneer from specimens which were brought back by the officials of the Congo F'ree State ('Bull. de Musée Royale d’Hist. Nat. de Belg,.' Brussels, 1886, iv, p. 103).

The marine appearance of the genus $\mathrm{Nassopsis}$ was pointed out by S. P. Woodward in 1857 , but with curious inconsistency he regarded this form as a Melania belonging to the sub-genus Melanella. It is to Smith that we owe the first definite assertion of the possibility that these Gasteropods 
1. That in the genera Bathanalia and Typhobia we have a type of Gasteropods which stands very much in the same relation to the modern Strombidæ that the early Equidæ do to the modern horse.

2. That in the so-called Spekia zonatus we have a form which even in its most minute anatomical details, as well as in its shell structure, is an unquestionable Naticoid of the Lamellarian type.

3. That the so-called Tanganyicia rufofilosa is closely related to the oceanic Planaxids, and that it is antecedent to a certain section of the heterogeneous Melanoid group, much in the same way that Littorina is antecedent to another.

4. That the genus Limnotrochus is really compounded

might, when their anatomy became known, turn out to be marine derivatives. Smith was unfortunate, however, in his forecast of the affinities of Typhobia as a Melania, since it is obvious, from the character of the radula of this mollusc alone, that it has no affinity with that group (see my figs., 'Quart. Journ. Micr. Sci.,' vol. 41, pt. 1, p. 189). Great credit is, however, due to Smith for his shrewd guess at the marine nature of the halolimnic shells with which he was then acquainted, and more especially so because he was not, as it were, frightened out of his better judgment as a naturalist by the existing geological preconceptions respecting the past history of the African interior. The later classification of the Tanganyika shells given by Bourguignat ('Ann. des Sci. Nat.,' t. x, pp. 1-267) is quite unintelligible either as to the means by which his endless species are distinguished from each other, or as to their affiliation in his so-called natural groups. Indeed, as an example of the utter confusion and obscuration of the facts which may be produced by the unrestrained application of the conchological method of determining molluscan affinities when the animals contained in shells are quite unknown, this work is perhaps unrivalled. In M. Fischer's excellent conchological treatise, on the other hand, there will be found a careful estimation in each case of the probable affinities of those Tanganyika shells which were known. But each of these is, of necessity, simply drawn from conchological data, and the caution with which the author proceeds in the absence of all morphological information is most marked. In order that the reader may obtain a clear conception of the points in which what may be called the newer classification given in the text of this paper differs from and extends that which could be arrived at by the study of the empty shells, I give here in parallel columns for comparison a list of the families and genera with which the Halolimnic Gasteropods are incorporated in M. Fischer's work, and those to which I should myself refer them after a study of the morphology of each. In this list I 
of two distinct types, one of which, represented by $\mathrm{L}$. Thompsoni, is closely similar to Bathanalia; while the other, represented by the unique L. Kirkii, is the only fresh-water Xenophora (Onustus) at present known.

5. That in the Paramelanian group, composed of the genera Paramelania, Nassopsis, and Bythoceras, we have forms

have used the family name Purpurinidæ to include the genera Paramelania, Nasopsis, and Bythoceras, and the new generic name Chytra for the old generic name of Limnotrochus, in the case of L. Kirkii.

Conchological Classification according to M. Fischer.

F am.-Melaniidæ.

Genus.-Typhobia (Smith).

T. Horei, Smith.

Genus.-Paramelania (Smith).

P. Damoni, Smith.

M. nassa, S. P. Woodw.

F a m.-Hydrobiidæ.

Genus.-? ? Syrnolopsis (Smith).

S. lacustris, Smith.

Genus.-Spekia (Bourguignat).

S. zonata, S. P. Woodw.

Genus.-Tanganyicia (Crosse).

T. rufofilosa, S. P. Woodw.

Genus.-Limnotrochus (Smith).

L. Thomsoni, Smith.

L. Kirkii, Smith.

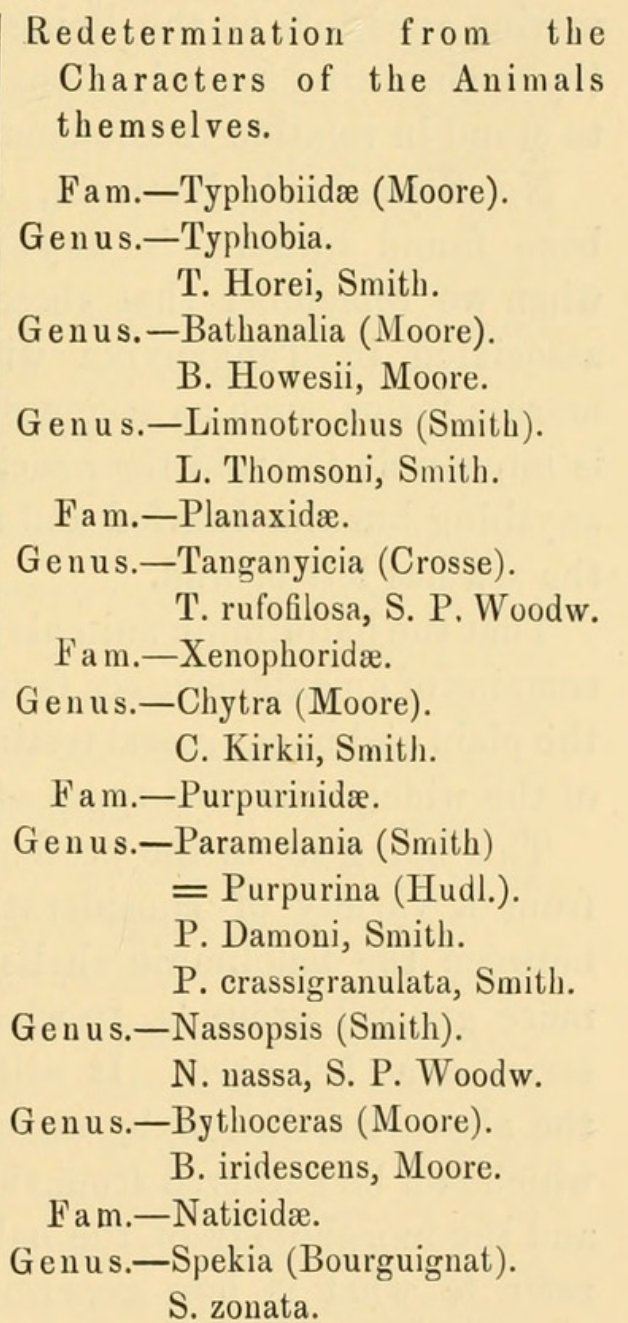

In the above list I have placed the genus Chytra among the Xenophoridæ on account of its conchological similarity to numerous fossils which are referred to this group.

The notes of interrogation in the older list are those of M. Fischer. 
which, judged by their anatomical (as well as by their conchological) features, do not appear to be living elsewhere now, but their shells approximate in a most remarkable degree to those of the extinct marine Jurassic genus Purpurina, whilst at the same time they possess the nervous system of a Cyclophorus. They thus appear not only to come of a marine stock, but also to indicate the hitherto unknown road by which the Cyclophoran nervous system has been evolved. These living Tænioglossa stand in much the same relation to their extinct marine ancestors as the living Cyclostoma has been shown (by the beautiful investigations of Lacaze-Duthiers and Bouvier) to stand in relation to the common periwinkle of our shores.

No Stromboid, Naticoid, or Xenophoran molluses have been found hitherto in any fresh water that is known; and when we remember that these truly marine Gasteropods are associated in Tanganyika with other and widely different marine forms, such as sponges, medusæ, crabs, and prawns, it is impossible to avoid the conclusion that these animals can be anything but the dwarfed and stunted remnant of a fauna that the sea has left behind.

That the halolimnic animals still living in Tanganyika are the remains of an extensive sea fauna that once existed there, is thus the plain and unequivocal testimony afforded by the morphology of the widely different types of which this fauna is composed.

This being so, in the present paper I shall attempt to show, from a variety of considerations relating to the similarity between the halolimnic shells and certain fossils, and upon more general grounds, to what old sea fauna the halolimnic series once belonged. It will probably have been seen that the above conclusion by no means exhausts the information which can be gathered from the joint study of the distribution and the morphology of the halolimnic group. We need only refer to what is now generally known respecting the gross physical features of the African continent, and especially of the regions about the great lakes, to see that it is impossible for most if not all the halolimnic forms either to have made their way up to, or to have been left in, Tanganyika in recent 
times. The lake is now 2700 feet above the level of the sea, and is more than 700 miles from any coast; there is but one effluent, and the course of this river is beset with rapids and with falls even long before it reaches the lower channels of the Congo on its way towards the sea; and finally, there are no true representatives of the halolimnic fauna, except, perhaps, the universal Xenophoridæ, in that part of the Atlantic into which the Congo flows.

The physiographical features of the continent point directly, therefore, to the conclusion that the halolimnic fauna must be very old. It must have been left in the great valley of Tanganyika long before that part of the continent had attained its present altitude, and when the surface of the water was approximately at the level of the sea. In exact conformity with this indication, it will have been seen that the halolimnic animals as they now exist, although closely allied to different marine genera, are not exactly similar to any oceanic species that we know ; and finally, it has been shown that the halolimnic Gasteropods, at any rate, stand in the relationship of immediate ancestors to several of our well-known oceanic forms. There thus exists evidence which appears to be practically conclusive that the halolimnic animals retain the facies of a sea fauna that has elsewhere disappeared, and consequently, unless they have become modified out of all semblance to their original marine progenitors, it is only natural to expect that on some marine fossiliferous horizon we shall again encounter in a fossilised condition similar molluscan shells. The hope that we may in this way be able actually to "locate" the halolimnic fauna of Lake Tanganyika with that particular marine stock from which it sprang is all the greater, on account of the very striking facies which the shells of the molluses belonging to it invariably present. But in actually searching among marine deposits for the particular sea fauna to which the halolimnic animals may correspond, it is essential that we bear in mind the caution that single comparisons are likely to be of little service as affording any indication that two such faunas are the same. There must be in the old stock, to which we are 
going to compare the halolimnic fauna, at least a sufficient number of types which are similar to individual halolimnic forms to correspond with a majority of the forms the halolimnic fauna now contains. I have emphasised this point because certain comparisons have already been instituted between the shells of the Paramelanias of Tanganyika and forms occurring in the fresh-water cretaceous beds.

In 1883, White, ${ }^{1}$ in an extremely short paragraph, pointed out that, speaking conchologically, there is not much to distinguish the shell of the genus Paramelania (Smith) from that belonging to the extinct fresh-water Pyrgulifera, which he obtained from the Green River deposits of the United States. So far as the outward forms of these shells go, there are slight differences as to sculpture, and so forth (compare Pl. 23, figs. 1 and 7 ). But $I$ do not know that such dissimilarities as these would justify even a conchologist in regarding the genera as distinct, and that this comparison of a single halolimnic and cretaceous shell is, in the absence of any possibility of information respecting the nature of the contained animals or their associates, "so far, so good," seems to be the total net result of the further observations made upon the subject by Tausch ${ }^{2}$ and Oppenheim, ${ }^{3}$ except that these latter authors appear to have had at their command more extensive and better preserved material than that which White examined. Speaking conchologically, then, there is one type in the cretaceous fresh-water deposits and one in the African halolimnic fauna which are similar in form. But even in the case of the single correspondence which presents itself Tausch's work appears to have rendered it extremely doubtful whether the two forms can be still considered as even conchologically the same. He showed, after examining hundreds of Pyrguliferas from the upper cretaceous beds from Ajka in Hungary, that

1 'Proc. U.S.A. Nat. Mus.,' S. 98, Washington, 1882, p. 98 (published in 1883).

2 'Sitz. Ber. d. k. Acad. Math. Wien,' 1885, Bd. xc, p. 57.

${ }^{3}$ Zeitschrift. der Deutsch. Geol. Gesell.,' 1892, Bd. xliv, p. 697; for diagnosis of Pyrgulifera see 'U.S. Geol. Surv.,' 40 parallel, vol. iv, p. 146, pl. 7, fig. 19. 
their shells could be sorted out into several groups which in their extreme forms were quite distinct, but which were really indissolubly connected together by innumerable transitional types. Thus one type of Pyrgulifera agrees with Paludomus Pichleri (Hoern.) from the "Gosauformation," another with P. armatus (Math.) from the French chalk, a third with P. lyra (Math.) from the same, a fourth with Pyrgulifera humerosa (Meek) from the Laramie of North America; while to a fifth and sixth Ajka variety there seem to be no known corresponding forms. Since all these types are stated by Tausch to run completely into one another, they can but be regarded as connected polymorphs of one and the same generic type, whatever the actual organisation of this genus may have been. Tausch further points out that in Paludomus Pichleri there are certain characters at the base of the mouth which have led to this shell being described both as a Paludomus and a Melanopsis. This melanopsid "mouth" is not found, according to Tausch, in P. Stephanus (Bens), but it is present in P.'humerosa and in the Paramelania Damoni of Tanganyika. Tausch therefore argues that the Paramelania Damoni, Pyrgulifera humerosa, and those forms of Paludomus which possess this peculiarity of "mouth" are, together with certain forms of Melanopsis, merely varieties of a single polymorphic type. This type embraces also in its other modifications forms approximating to Melania amarula, Lamarck's type of the genus Melania. I can fully confirm the observation of the remarkable similarity of some of the Pyrguliferas collected by Dr. Oppenheim, and now in the British Museum, to M. amarula; in fact, some of these forms approximate far more closely to the living M. amarula of Madagascar than they do to the Paramelania of Tanganyika. Thus, whatever the dead Pyrgulifera may have been, its shells in their different modifications agree with a great number of living types, and if it be really legitimate to draw any conclusion from this complexity of corresponding forms, it can only be said that Tausch's work has shown that there appears to have existed in the fresh water 
of the upper cretaceous series a form which united by insensible gradations the conchological characters of Melanopsis, Paludomus, Pyrgulifera, Melania (amarula) and Paramelania. But if on this ground it should be maintained that the living representatives of these different groups have any immediate phylogenetic relationship with each other, all that can be said by anyone acquainted with the morphology of such of them as now exist must be that although a deduction of this kind from the characters of living and extinct shells may be conchologically correct, it is also at the same time morphologically nonsense; there is no sort of morphological similarity between Melanopsis and a Melania amarula. These forms, as the investigations of Bouvier have shown, should by right be placed in different families. Paludomus differs from them both, while the Paramelania of Tanganyika is altogether unlike any of the three. Thus if the genus Pyrgulifera corresponds to any of these types which now exist, it differs from all the rest which I have named. If Pyrgulifera humerosa was morphologically similar to Melanopsis, it was not a Paramelania. If, on the other hand, it was a Paramelania, it was neither a Melampus paludomus nor a Melania proper. There is thus really no direct reason why the Pyrgulifera of the chalk should not have been a Paramelania; but since the genus Pyrgulifera has been shown by Tausch to correspond equally to three widely distinct living types, it is clearly more than three to one that such was not the case.

As to the question of the identity of the entire fresh-water fauna with which the Pyrguliferas are connected in the upper chalk, and that consisting of the halolimnic group in Tanganiyka, whether we regard the Paramelanias and Pyrguliferas as similar or not, it will be obvious that as there are no other forms in these faunas bearing the slightest resemblance to one another, the question of their general identity is ipso facto out of court. Not only do the halolimnic animals differ from those of the fresh-water fauna individually, but the whole halolimnic fauna differs entirely from the cretaceous or any 
other fresh-water stock in the general facies it presents. These old cretaceous beds present the facies of a true fresh-water fauna, otherwise they could not be identified as such; they contain no crabs or prawns, there are no impressions of jellyfish in the soft grey mud of which they are generally composed; they contain no shore sponges, Lamellariidæ, no Xenophoridæ or other marine Gasteropods, all of which are still living in the slightly brackish water of Tanganyika at the present time. In fact, the halolimnic fauna differs from that occurring in these fresh-water cretaceous beds just in those features which distinguish fresh-water from marine stocks in general, and there is not the slightest doubt that had the halolimnic fauna occurred fossilised it would have been regarded as unquestionably marine.

The halolimnic fauna of Tanganyika, then, is not the remnant of a cretaceous fresh-water stock, neither is it like any cretaceous marine fauna which we know, nor is it represented in any of the upper Mesozoic beds. It is only when we compare the shells of the halolimnic molluses with those in several of the lowest secondary formations that any substantial similarity appears.

In fig. $1 \mathrm{~A}$, are represented two remarkably fine examples of the marine Jurassic genus Purpurina; the figure is copied from a specimen P. bellon a courteously placed at my disposal for this purpose by Mr. Hudleston from his magnificent collection of Jurassic fossils. The genus has a somewhat curious history in literature, which will be found fully dealt with in Mr. Hudleston's ${ }^{1}$ monograph, 'The Jurassic Gasteropoda.' As amended in this work for P. elaborata, the diagnosis of the genus runs as follows:

"Shell ovate conoidal, apex acute, whorls about five or six, posterior area tabulate, sides moderately tumid. The ornaments consist of about eighteen longitudinal costæ, which are feebly developed on the tabular area, rise up into spinous nodes on the keel, and are strong and regular on the flanks of the whorls. The costæ have a tendency to die out anteriorly on the body-whorl; the costæ decussate with regular and closely

1 'A Monograph of the British Jurassic Gasteropoda.' Palæont. Soc., 1887, Part 1, No. 2, p. 86. 
set spirals, which extend down to the base of the shell. No spirals are seen on the flat area. Aperture oval to subquadrate, columella moderately reflexed, so as to produce anteriorly a wide and shallow groove towards the point. Umbilical slits scarcely indicated."

Side by side with these old Jurassic shells I have had drawn two corresponding views of Smith's Paramelania Damoni from Tanganyika (fig. 1), the generic diagnosis of which runs as follows :

"Shell solid, ovate, conical, imperforate, longitudinally ribbed, transversely lyrate, covered with a thin epidermis. Aperture ovate, entire, indistinctly effuse at the base, last whorl sometimes slightly prolonged inferiorly. Peristome thick, margins joined by a callosity, operculum like that of Typhobia."

The striking similarity of the two shells from these descriptions will be at once apparent; in fact, as $\mathrm{Mr}$. Hudleston remarked while we were examining the recent shells and fossil side by side, "they are not only generically the same, but specifically identical."

The shells of the genus Paramelania were, however, shown by the German authors I have quoted to be similar to the Cretaceous genus Pyrgulifera, and, as objects which are like the same thing are necessarily like each other, it becomes a question for the systematists and the conchologists whether or not the genus Pyrgulifera and Paramelania should be quashed, and both replaced by the older genus Purpurina. There are slight differences between the shells of the genera Pyrgulifera, Purpurina, and Paramelania when they are carefully examined side by side; but these are not at all sufficient to separate the specimens from one another as specifically distinct, and, as Dr. Woodward pointed out to me, those of the genus Paramelania approximate more closely to the shells of the Jurassic genus Purpurina than they do to the more recent Pyrgulifera type.

In Hudleston's monograph there are represented two rather 1 ‘Proc. Zool. Soc.,' 1881, p. 559. 
distinct types of Purpurina shell, one characterised by the P. bellona (fig. 1A), the other by the P. inflata given in fig. $2_{\mathrm{A}}$. Hudleston did not separate these forms as generically distinet, but figured the types of which they are characteristic on separate plates. How closely similar this inflata type of Purpurina is to the living $\mathrm{Nas}$ sopsis of Tanganyika will at once be apparent from figs. 2 and $2_{A}$. The genus $\mathrm{Nassopsis}$ was separated by $\mathrm{Smith}^{1}$ from Paramelania on account of the difference in the operculum, but it is doubtful if this distinction can be maintained from their anatomy ; indeed, I should be inclined to place Paramelania, Bythoceras, and Nassopsis as species of one new family, the Paramelanidæ. The fact that there is more constant distinction between the Tanganyika $\mathrm{P}$ aramelania and Nassopsis now than that which used to exist between the bellona and inflata types of Purpurina is just what we might expect, since it is probable that these two forms would become less transmutable as time went on. ${ }^{2}$

The Tanganyika Paramelania and $\mathrm{Nassopsis}$ are thus identical with two forms occurring in the old Jurassic beds, and the Paramelania corresponds more closely to the Bellona type of Purpurina than it does to the Pyrgulifera of the chalk.

In the same Jurassic series there is another characteristic genus, Amberlya, which is specifically very variable in size, sculpture, and in the character of its spines. Two forms are represented in fig. $3 \mathrm{~A}$, the upper one from the collection in the British Museum, the lower from Mr. Hudleston's collection. The history of this genus Amberlya is peculiar and instructive, and will be found fully set forth in Hudleston's monograph. ${ }^{3}$ The genus was originally founded by Morris and Lycett, but was subsequently modified by Hudleston, and

1 'Proc. Zool. Soc.,' 1881, p. 559.

2 There is a peculiarity in the base of the columella of some of the $\mathrm{N}$ as sopsis shells which is not represented in those of the genus Purpurina, but which is a permanent feature of the Jurassic Monodonta. So far as Nassopsis goes this is an unimportant feature, since it is not constant in the genus.

${ }^{3}$ Loc. cit., part 1, No. 6, pp. 274-279. 
as amended by him the diagnosis runs-"Shell turbinate, more rarely trochoid, rather thin, imperforate or nearly so; subelongate, frequently turreted; sutural space wide; ornamented with spiral bands, usually spinulous or nodular, some of which are prominent. The interspaces are finely striated, the striæ being slightly oblique to the axis; sometimes these fine lines are strong enough to represent fine axial ribs. Base rounded, spirally ribbed, and marked by fine radial striæ ; aperture suboval, but varying according to age, in the adult more or less rounded, so as to become suboval or subcircular; there is usually a considerable deposit of callus; outer lip thin, often crenulate."

This description would certainly answer for that of one of the new types which I found in Tanganyika, and for which I have proposed the generic name Bathanalia (fig. 3), for although the Jurassic genus A mberly a shows a considerable range of specific variation, all its species have essentially the same characteristics as the two represented in fig. $3 \mathrm{~A}$, upper and lower. The thin shell, the absence of all trace of epidermis, and the character of the whorls, as well as the sculpture and the character of the mouth, are all essentially the same in Bathanalia as they are in Amberlya; the only point in which they differ is in the columella, that of Bathanalia being generally open, while that of A mberly a is always closed. I have, however, consulted Mr. Edgar Smith and others about this, and he assures me that such differences cannot be upheld as generically distinctive, more especially as the amount of umbilical opening in Bathanalia varies a good deal in extent from shell to shell. We may, therefore, conclude that conchologically Bathanalia and Amberlya are the same.

The next example of the close similarity existing between the living shells in Tanganyika and the marine Jurassic types is that afforded by the Limnotrochus Thompsoni of the one and certain so-called Littorinas of the other. In fig. 5 are represented two views of $\mathrm{L}$. Thompsoni, while in fig. $\mathbf{5}_{\mathbf{A}}$ are given similar views of the Jurassic species Littorina sulcata. 
Smith's generic diagnosis of Limnotrochus runs thus:"Shell trochoid, umbilicated, without an epidermis, spirally ribbed; body-whorl keeled round the middle; aperture nonlyrate within; with the outer lip oblique, the basal margin broadly sinuated, and the columella edge somewhat reflexed. Operculum horny, paucispiral, litterinoid."l This description would not do for the living Littorinas of our shores, but it covers the two forms, one from Tanganyika and the other from the marine Jurassic beds, just described.

I would next direct attention to the very obvious conchological similarity between the so-called Limnotrochus Kirkii (fig. 6) and the marine genus Xenophora (Onustus), a form which has extended in the ocean from the Devonian to the present time. This genus is not, therefore, typical of the Jurassic period, specially those which I have already described, but it forms one more remarkable example of the marine character of the halolimnic forms. I have represented side by side the L. Kirkii (fig. 6) and an example of Onustus (fig. 6 A), a typical Jurassic form. ${ }^{1}$

I have already stated that the so-called Lithoglyphus (Spekia) zonatus of Tanganyika (fig. 4) is unquestionably, from the characters of its anatomy, a Naticoid ; and in the inferior Oolite there are forms which it would be quite legitimate to regard as coming near this genus. To illustrate this fact I have figured the so-called Neridomus (fig. $4 \mathrm{~A}$ ) of the inferior Oolite, the affinities of which are doubtful in a high degree.

Lastly, in Tanganyika there exists a remarkable longitudinally sulcated shell known as Melania admirabilis (Smith); how closely this form corresponds to those remarkable Oolite shells known as Cerithium subscalariforme will be seen on comparing their respective shells. I did not find this species myself in Tanganyika, and as the animal it contains is not

1 'Proc. Zool. Soc.,' 1881, p. 285.

${ }^{2}$ It is needless for me to point out that the two forms of Xenophora here figured from Tanganyika and from the Inferior Oolite are not specifically the same. The so-called Limnotrochus Kirkii of Tanganyika being much more like several modern examples of the genus Onustus (Xenophora). The figures only illustrate the general similarity of such shells.

VOL. 41, PART 2 , - NEW SERIES. 
known I have not thought it necessary that I should give figures of them here.

Besides the above marine types the halolimnic fauna contains two forms, Syrnolopsis and Turbonella terebriformis, which, although they do not resemble any known Jurassic shells, nevertheless exemplify in a remarkable manner the marine affinities of the halolimnic mollusca as a whole; for the shell of the first of these species is practically undistinguishable from that of the genus Syrnola, a form found in the tropical seas, the second from that of the genus Terebra.

It is thus apparent that with the exception of Typhobia, and possibly of Bythoceras, all the halolimnic genera now living in Lake Tanganyika are generically identical with Jurassic forms, while two of these, Paramelania and Nassopsis, contain forms which are specifically indistinguishable from their corresponding Jurassic types.

Curious and startling as the foregoing comparison undoubtedly appears, I might still have had some hesitation in bringing it forward as evidence of the origin of the halolimnic fauna, had not the three authors, White, Tausch, and Oppenheim, practically forced my hand by attempting the comparison of which I have spoken between the living halolimnic and the old cretaceous fresh-water stocks. Whatever may be the real value of evidence which is based upon shell structure alone (and this certainly becomes more and more questionable as time goes on), it will have been rendered clear that the amount of this kind of evidence favouring the similarity of the halolimnic and old cretaceous fresh-water stocks is utterly insignificant beside that which can be produced in favour of the similarity of the halolimnic and old marine Jurassic forms.

So far as I am concerned, therefore, this paper will have

1 The genus Typhobia, as I have shown, is, however, closely related to Bathanalia, and there is very little doubt that it simply represents a modification of the former form. It may be that the genus Typhobia in reality represents the Jurassic form Purpuroidea. 
fulfilled its purpose if it acts merely as a sort of counterpoise to the altogether disproportionate importance which has been attached to the apparent similarity between the Paramelania of Lake Tanganyika and the Pyrgulifera of the upper chalk.

Whatever opinion those competent to judge may form of the comparisons which I have just instituted between the marine Jurassic and the halolimnic faunas, it is obvious that these comparisons are nothing like so rash an undertaking as that attempted by the three authors I have named. The view that the Tanganyika fauna corresponds to a fresh-water cretaceous stock rests on nothing but the similarity of a single type of shell common to the halolimnic and cretaceous fresh-water series; and, as we have seen, the possibility of even this single point of similarity being due to anything more than mere convergence of external form has been rendered so extremely doubtful by the more extended observations which one of the authors named has already made, that any attempts to pursue the question further would be simply waste of time. Even if the far more weighty evidence for the correspondence of the halolimnic fauna with that of the Jurassic seas rested solely on the similarity of their respective shells, although such evidence would be as good as that forthcoming for many sweeping geological deductions, I should, for my part, be highly sceptical that it afforded any trustworthy indication that the hypothesis is true. When, however, we view the supplementary facts of this comparison, when we regard it in the light of what I have ascertained respecting the distribution, and especially the comparative morphology of the halolimnic forms, it is very clearly apparent that the theory of their similarity is not without much collateral support.

We know now that the morphological characters of the halolimnic fauna are those of an early oceanic stock, that they do not stand midway between the living fresh-water faunas and their marine beginnings, for they do not foreshadow any known fresh-water types; on the other hand, we have seen that they do very distinctly foreshadow many living oceanic types, each individually uniting the characters of several modern oceanic 
species. We are sure, therefore, that the halolimnic group represents an old sea stock that became detached from the general oceanic fauna of which it was a part, far back in time. Like the Oolite molluscs, those of this halolimnic fauna have a striking type of shell, and when, after reviewing the facies presented by the marine fauna of the successive geological periods, we find such types represented abundantly nowhere except in the Jurassic seas, and that these seas present forms corresponding to them all, the comparison appears to be something more than a mere coincidence. It rather appears as the fulfilment of an expectation raised simultaneously by the three chief lines of search relating to their distribution, morphology, and affinity with existing types.

I offer this comparison, therefore, as the probable explanation of the singularly interesting problem presented by the mixed fauna which Tanganyika now contains, and I have all the more confidence in so doing since much study of the question, in the light of every suggestion which I could either invent or borrow, has convinced me that no other even momentarily tenable explanation is likely to be found.

\section{DESCRIPTION OF PLATE 23,}

Illustrating Mr. J. E. S. Moore's paper "On the Hypothesis that Lake Tanganyika represents an Old Jurassic Sea."

FIg. 1.-Front and back view of the shell of Paramelania Damoni (Smith), Tanganyika.

FIG. 1A.-Front and back view of the shell of Purpurina bellona (Hudl.), the corresponding Jurassic form.

FIg. 2.-Front and back view of the shell of Nassopsis nassa (Smith), Tanganyika.

FIG. 2A.-Front and back view of the shell of Purpurina inflata (Hudl.), the corresponding Jurassic form. 
Fig. 3.-Front and back view of Bathanalia Howsei (Moore), Tanganyika.

FIg. 3A.-Upper figure, back view of A mberlya, sp.? from the Inferior Oolite, British Museum ; lower, front view of A mberlya, sp. ? from the Lias, the corresponding Jurassic forms.

FIG. 4.-Front and back view of Spekia zonatus (Woodward), Tanganyika.

Fig. 4a.-Front and back view of Niridomus minutus, var. tumidulus (Phill.), the corresponding Jurassic form.

Fig. 5.-Front and back view of Limnotrochus Thompsoni (Smith), Tanganyika.

Fig. 5A.-Front and back view of Littorina sulcata, the corresponding Jurassic form.

Fig. 6.-Back view and base of Limnotrochus Kirkii (Smith), Tanganyika.

Fig. 6A.-Back view and base of Xen ophora (Onust us), from the Inferior Oolite.

Fig. 7.-Back view of the shell of Pyrgul if era humerosa (Meek), from the fresh-water deposits of the upper chalk. 


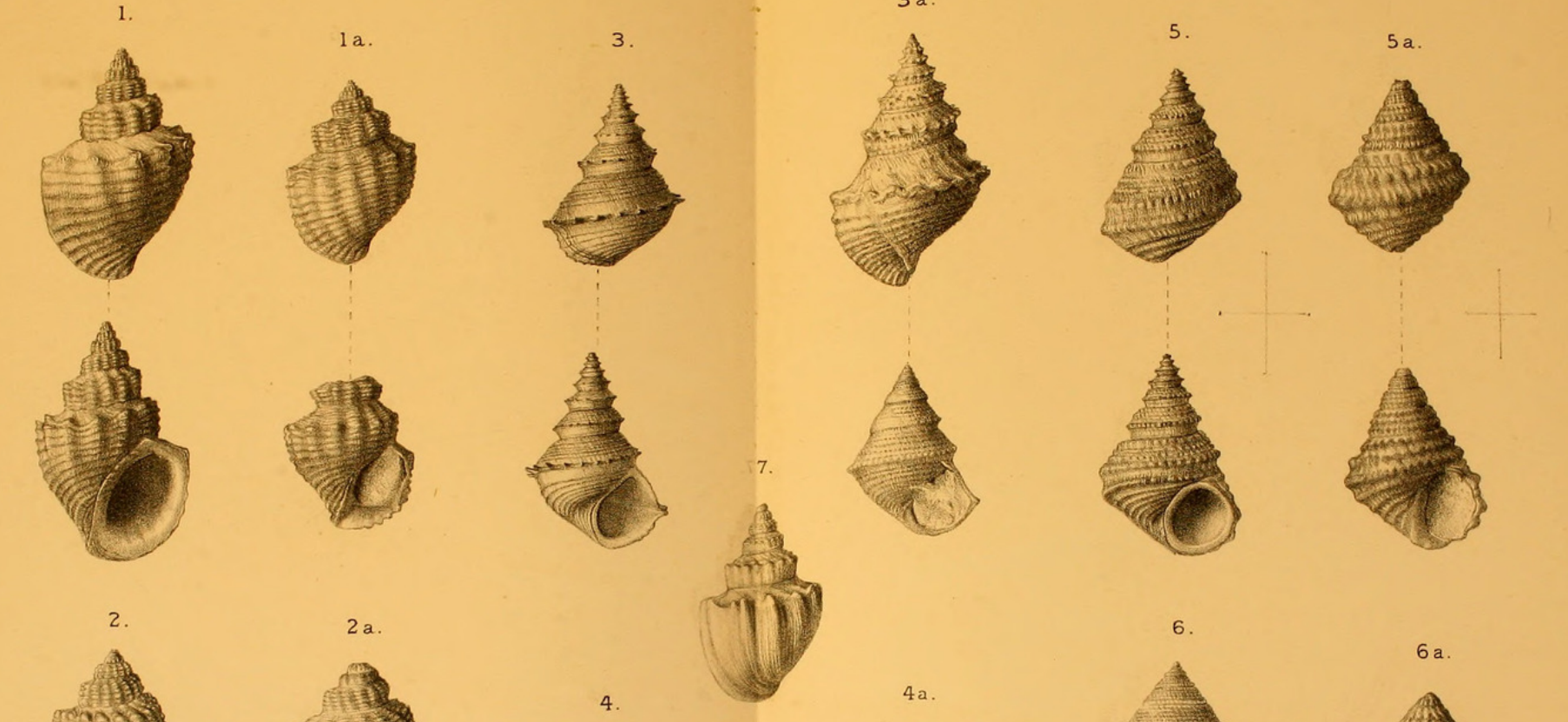

$$
\begin{aligned}
& \text { - } 001 \\
& \text { (b) (1) (1) }
\end{aligned}
$$




\section{$2 \mathrm{BHL}$ Biodiversity Heritage Library}

Moore, J E S. 1898. "On the Hypothesis that Lake Tanganyika represents an Old Jurassic Sea [Text]." Quarterly journal of microscopical science 41, 303-321. https://doi.org/10.5962/bhl.part.1223.

View This Item Online: https://www.biodiversitylibrary.org/item/48928

DOI: https://doi.org/10.5962/bhl.part.1223

Permalink: https://www.biodiversitylibrary.org/partpdf/1223

\section{Holding Institution}

Harvard University, Museum of Comparative Zoology, Ernst Mayr Library

\section{Sponsored by}

Harvard University, Museum of Comparative Zoology, Ernst Mayr Library

\section{Copyright \& Reuse}

Copyright Status: Public domain. The BHL considers that this work is no longer under copyright protection.

This document was created from content at the Biodiversity Heritage Library, the world's largest open access digital library for biodiversity literature and archives. Visit BHL at https://www.biodiversitylibrary.org. 